\title{
High Risk of Infection During Triple Therapy with First- Generation Protease Inhibitors: A Nationwide Cohort Study
}

\author{
Floor A.C. Berden ${ }^{1}$, Inke M.J.M. van Zwietering ${ }^{1}$, Raoel Maan ${ }^{2}$, Robert J. de Knegt ${ }^{2}$, Wietske Kievit ${ }^{3}$, Joost P.H. Drenth ${ }^{1}$
}

1) Department of

Gastroenterology and

Hepatology, Radboud

University Medical Center,

Nijmegen,

2) Department of

Gastroenterology and

Hepatology, Erasmus MC

University Medical Center,

Rotterdam,

3) Department of Health

Evidence, Radboud University

Medical Center, Nijmegen,

The Netherlands
Address for correspondence: Prof. Joost P.H. Drenth

Department of

Gastroenterology and

Hepatology

Radboud University

Medical Center

P.O. Box 9101 , code 455

6500 HB Nijmegen,

The Netherlands

joostphdrenth@cs.com

Received: 13.04 .2016

Accepted: 17.05.2016

\begin{abstract}
Background \& Aims: Peginterferon (PegIFN) remains the backbone of therapy for chronic hepatitis C (CHC) in economically constrained regions. However, PegIFN may cause neutropenia and addition of a protease inhibitor can increase the likelihood of neutropenia. The aims of this study were to assess the occurrence of clinically relevant infections during first-generation protease inhibitor based therapy and its risk factors as well as the relation to treatment-induced neutropenia.

Methods: This multicenter $(n=45)$ retrospective cohort study included CHC patients treated in the Netherlands. Based on absolute neutrophil count, categories of neutropenia were defined as: severe $(<500 / \mu \mathrm{L})$, moderate (500-750/ $\mu \mathrm{L})$ and mild $(750-1500 / \mu \mathrm{L})$. Likewise, infections were classified as severe (intravenous antibiotics/ hospitalization) and moderate (anti-infective treatment). We assessed risk factors for infections using multivariable regression analysis with correction for multiple measurements.

Results: We included 467 CHC patients, 319 (68\%) were male and 111 (24\%) had cirrhosis. A total of 185 clinically relevant infections (34 severe) occurred in 145 patients (31\%). During treatment 310 patients experienced neutropenia (34 severe). Multivariable analysis identified female sex (OR 1.7, 95\%CI 1.2-2.5), chronic obstructive pulmonary disease (COPD) (OR 2.7, 95\%CI 1.6- 4.5) and diabetes mellitus (OR 1.7, $95 \% \mathrm{CI} 1.0-3.0)$ as risk factors for infections. Neutropenia at the previous visit was not associated with infection (univariable analysis: OR 0.9, 95\%CI 0.6-1.3).

Conclusion: This study shows that therapy with first generation protease inhibitors was complicated by an infection in $31 \%$ of patients. Not neutropenia, but female sex, COPD and diabetes mellitus were independent risk factors for infection. These patients should be monitored carefully once a PegIFN regimen is initiated.
\end{abstract}

Key words: antiviral agents - boceprevir - telaprevir - hepatitis C infection - neutropenia - risk factors.

Abbreviations: ANC: absolute neutrophil count; CHC: chronic hepatitis C; COPD: chronic obstructive pulmonary disease; DAAs: direct acting antivirals; DM: diabetes mellitus; HCV: hepatitis C virus; PegIFN: pegylated interferon alpha; PI: protease inhibitor; UTI: urinary tract infection.

\section{INTRODUCTION}

For many years pegylated interferon alpha (PegIFN) has been the backbone of chronic hepatitis $\mathrm{C}(\mathrm{CHC})$ treatment. The introduction of the firstgeneration direct acting antivirals (DAAs), telaprevir and boceprevir, initiated a cascade of developments of new generation DAAs [1]. From 2014 onwards, PegIFN-free treatment options with higher cure rates and better tolerability have become available in many western countries [2]. These new PegIFNfree regimens are very costly, limiting the availability in many economically deprived regions worldwide, where the majority of the global CHC population resides [3-6]. Guidelines still recommend telaprevir and boceprevir for use in countries where new generation DAAs are not available. Therefore, triple therapy still maintains its therapeutic value $[7,8]$.

One of the drawbacks of triple therapy is its high rate of adverse events, which often can be attributed to the use of PegIFN. Neutropenia is frequently reported and mainly caused by bone marrow suppression $[9,10]$. To prevent infections, product labels and guidelines advise dose reductions or even discontinuation of treatment if neutrophil count drops below $750 / \mu \mathrm{L}$ or $500 / \mu \mathrm{L}$, respectively $[7,11]$. However, prior studies in $\mathrm{CHC}$ patients undergoing (Peg)IFN and ribavirin 
(RBV) therapy did not find an association between treatmentinduced neutropenia and infections, while dose reductions of PegIFN can reduce effectiveness [12-17]. The situation may be different with triple therapy, because phase III studies found that the inclusion of boceprevir to the $\mathrm{CHC}$ treatment strategy increased the likelihood of neutropenia compared to PegIFN and RBV $[18,19]$. In addition, comparative studies found more neutropenia in boceprevir than telaprevir treated patients [20, 21]. Real world data furthermore suggest that triple therapy substantially increases the risk of severe infections. However, the current evidence for this association is limited to $\mathrm{CHC}$ patients with cirrhosis [22-24]. Therefore, the aims of this study were (i) to investigate the occurrence and risk factors for clinically relevant infections and (ii) the relation of ontreatment neutropenia with infections in $\mathrm{CHC}$ patients who received triple therapy with boceprevir or telaprevir.

\section{METHODS}

\section{Population and design}

This nationwide, multicenter, real world cohort study included patients with $\mathrm{CHC}$ genotype 1 infection treated with telaprevir or boceprevir and PegIFN and RBV in the Netherlands (20112015) [unpublished data]. Patients across all fibrosis stages were included. We retrospectively identified patients from local databases, and excluded patients with a co-infection with human immunodeficiency virus or hepatitis B virus. Treatment choice between telaprevir and boceprevir was at the discretion of the physician and it was administered according to national guidelines [25]. We conducted the study in accordance with good clinical practice (GCP) guidelines, and the code of conduct for medical research (www.federa.org). Approval from participating centers was obtained following local regulations.

\section{Outcomes and definitions}

The primary outcome of this study was the occurrence of infections during treatment up to four weeks after cessation of treatment. Secondary outcomes were occurrence and severity of neutropenia, risk factors for infection, and severity of infection. In addition, the time until occurrence of the first infection after start of treatment was assessed. Infections were classified as severe in case of hospitalization or intravenous antibiotics, moderate if oral or topical anti-infective agents were administered and mild if no treatment was given. Moderate and severe infections were considered clinically relevant. Based on the thresholds for dose reduction and treatment discontinuation of PegIFN, we distinguished three categories of neutropenia: severe if absolute neutrophil count (ANC) was below $500 / \mu \mathrm{L}$, moderate if $\mathrm{ANC}$ was between 500 and $750 / \mu \mathrm{L}$ and mild if ANC was between 750 and $1500 / \mu \mathrm{L}[13,25]$. We used Fib- $4>3.25$ to classify patients as cirrhosis, because of its high performance in detecting cirrhosis and high availability of included biomarkers in the general population [26]. History of decompensated liver disease was defined as a history of ascites, variceal bleeding or hepatic encephalopathy.

\section{Data acquisition}

We collected all details on demographics, disease characteristics, infectious (serious) adverse events, and laboratory values. Laboratory values included hematological tests, creatinine, aminotransferases, and indicators of liver function. If two infections occurred within the same timeframe, we only included the most severe infection.

\section{Statistical analysis}

We described categorical variables as proportions and continuous variables as means (standard deviation, SD) or medians (interquartile range, IQR). The Kaplan-Meier method was used to assess time till occurrence of the first infection and the cumulative incidence rates of infections at 12 and 24 weeks after treatment initiation. Those time points were chosen as the introduction of new generation DAAs allows shortened use of PegIFN for 12 or 24 weeks [7]. Chi-square tests were performed to compare occurrence of at least one clinically relevant infection between subgroups of patients with and without diabetes mellitus (DM), chronic obstructive pulmonary disease (COPD) and cirrhosis. To identify predictors for clinically relevant infections we performed univariable and multivariable logistic regression analyses with correction for multiple measurements within a patient. Variables with a p-value $\leq 0.2$ in univariable analysis were included in multivariable analysis together with age, sex, cirrhosis and DM as fixed factors (backward stepwise method, complete cases). ANC at the visit prior to the occurrence of infection was included in univariable analysis. Odds ratios (OR) with 95\% confidence intervals $(95 \% \mathrm{CI})$ are reported. As a sensitivity analysis, all reported infections were included.

All analyses included the intention to treat population, and all tests were two-sided with a significance level of $\mathrm{p}<0.05$. The analyses were performed using SPSS (IBM SPSS Statistics 20) and SAS 9.3 (SAS Institute, Cary, NC, USA).

\section{RESULTS}

\section{Population}

Our cohort study included 489 patients in total, of which 22 were excluded. Therefore, 467 patients from 45 centers in the Netherlands were analyzed (Supplementary figure 1). Patients were treated with telaprevir $(n=265)$ or boceprevir $(n=202)$ and PegIFN and RBV. Mean age was 51 years (range 19-77), $319(68 \%)$ patients were male, and 111 (24\%) patients presented with cirrhosis. Baseline characteristics are shown in Table I.

\section{Infections}

In total, 233 infections in 171 patients were reported (34 severe, 151 moderate, and 47 mild), and thus 185 were clinically relevant occurring in 145 patients (31\%). A total of 79 of 265 telaprevir treated patients experienced 103 infections and 66 of 202 boceprevir treated patients experienced 82 infections. Incidence and severity of infections were similar for telaprevir vs. boceprevir ( $p=0.35$, Fig. 1). Main sites of infection were dermatological, respiratory, and gastro-intestinal (Table II). In total, 34 severe infections were observed in 31 patients (21 telaprevir and 10 boceprevir treated patients). Sites and diagnoses of severe infections are listed in Table III. Among patients with DM, COPD or cirrhosis, more infections were reported than in patients without DM, COPD or cirrhosis (DM: $46 \%$ vs. $29 \%, \mathrm{p}=0.012$; COPD: $57 \%$ vs. $29 \%, \mathrm{p}<0.001$; 
Table I. Baseline characteristics of the patients

\begin{tabular}{|c|c|c|c|}
\hline Characteristic & Overall $(n=467)$ & No infection $(\mathrm{n}=322)$ & Infection $(\mathrm{n}=145)$ \\
\hline Age, years - mean (range) & $51(19-77)$ & $50(19-77)$ & $52(25-74)$ \\
\hline Male sex $-\mathrm{n}(\%)$ & $319(68)$ & $234(73)$ & $85(59)$ \\
\hline White race $-\mathrm{n}(\%)^{\mathrm{a}}$ & $321(89)$ & $225(89)$ & $96(91)$ \\
\hline \multicolumn{4}{|l|}{ HCV genotype $-\mathrm{n}(\%)$} \\
\hline Genotype 1 indeterminate & $86(18)$ & $64(20)$ & $22(15)$ \\
\hline Genotype 1a & $226(48)$ & $158(49)$ & $68(47)$ \\
\hline Genotype $1 \mathrm{~b}$ & $155(33)$ & $100(31)$ & $55(37)$ \\
\hline Treatment naive $\mathrm{e}^{\mathrm{b}}$ - $\mathrm{n}(\%)$ & $273(60)$ & $190(61)$ & $83(58)$ \\
\hline Fib 4 index - median (IQR) & $1.8(1.1-3.3)$ & $1.6(1.1-2.9)$ & $2.1(1.3-4.1)$ \\
\hline Fib $4>3.25-\mathrm{n}(\%)^{\mathrm{c}}$ & $111(25)$ & $67(22)$ & $44(32)$ \\
\hline History of decompensated liver disease $-\mathrm{n}(\%)$ & $24(5)$ & $9(3)$ & $15(10)$ \\
\hline Diabetes mellitus n (\%) & $54(12)$ & $30(9)$ & $24(17)$ \\
\hline Chronic obstructive pulmonary disease - $\mathrm{n}(\%)$ & $37(8)$ & $16(5)$ & $21(14)$ \\
\hline Telaprevir vs. boceprevir & 265 vs. 202 & 186 vs. 136 & 79 vs. 66 \\
\hline \multicolumn{4}{|l|}{ Laboratory values $^{\mathrm{d}}$} \\
\hline Hemoglobin g/dL - mean (SD) & $9.1(0.9)$ & $9.2(0.9)$ & $9.0(0.9)$ \\
\hline Leucocyte count per $\mu \mathrm{L}$ - mean (SD) & $6727(2154)$ & $6827(2152)$ & $6500(2151)$ \\
\hline Neutrophil count per $\mu \mathrm{L}$ - mean (SD) & $3454(1532)$ & $3467(1503)$ & $3423(1606)$ \\
\hline Platelet count $\times 10^{9} / \mathrm{L}-$ mean (SD) & $192(76)$ & $198(78)$ & $179(71)$ \\
\hline Albumin g/L - mean $(S D)$ & $41.4(4.9)$ & $41.8(4.6)$ & $40.7(5.5)$ \\
\hline Total bilirubin g/dL - median (IQR) & $10.0(7-14)$ & $10(7-14)$ & $10(7-16)$ \\
\hline
\end{tabular}

${ }^{a}$ Race: available in 360 patients (252 without infection, 108 with infection); ${ }^{b}$ Previous response: available in 454 patients (310 without infection, 144 with infection); ${ }^{c}$ Fib-4 index: available in 438 patients (301 without infection, 137 with infection); ${ }^{\mathrm{d}}$ Lab values $>10 \%$ missing at baseline: neutrophil count, albumin

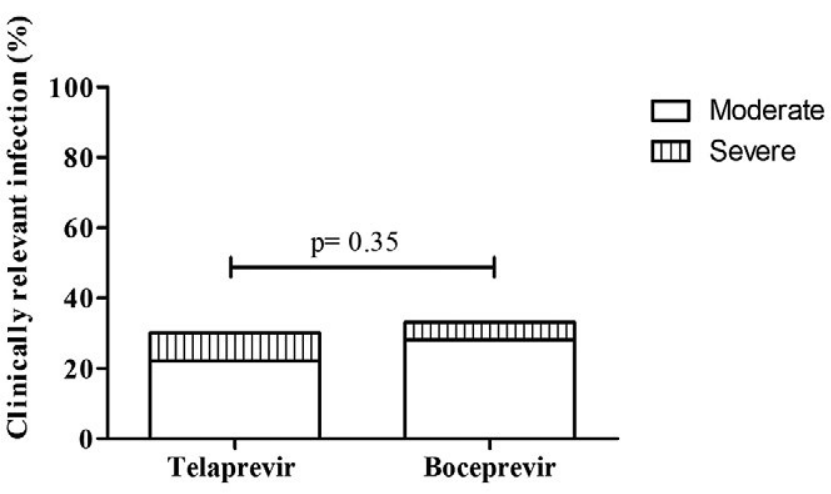

Fig. 1. Severity of infection in telaprevir and boceprevir-treated patients. The bars represent the percentage of patients who experienced a clinically relevant infection. A total of 79 patients treated with telaprevir and 66 patients treated with boceprevir experienced an infection.

cirrhosis $40 \%$ vs. $28 \%, p=0.024$; Fig. 2). Infection resulted in death in two patients: one patient was admitted with anemia and sepsis (bloodculture: Klebsiella and Staphylococcus Aureus) and died in hospital while the other patient died from a mycotic endocarditis (bloodculture: Candida Parapsilosis). The median time to develop a clinically relevant infection was 14 weeks (IQR 6-26 weeks). Cumulative incidence of infection within first 12 weeks was $17.4 \%$ (95\%CI 12.9-21.9) for telaprevir treatment and $12.6 \%$ (95\%CI 7.9-17.3) for boceprevir treatment (Fig. 3). Overall, no significant differences were seen
Table II. Categories of clinically relevant infections (moderate and severe)

\begin{tabular}{lccc}
\hline Site of infection & $\begin{array}{c}\text { Total } \\
\text { infections }\end{array}$ & $\begin{array}{c}\text { Moderate } \\
\text { infection }\end{array}$ & $\begin{array}{c}\text { Severe } \\
\text { infection }\end{array}$ \\
\hline Dermatological & 45 & 40 & 5 \\
Respiratory & 43 & 29 & 14 \\
$\begin{array}{l}\text { Gastro-intestinal } \\
\text { (incl. oral infections) }\end{array}$ & 38 & 36 & 2 \\
Renal - Urinary tract & 24 & 22 & 2 \\
Ear Nose Throat & 10 & 10 & 0 \\
General & 9 & 4 & 5 \\
Ophtalmology & 5 & 4 & 1 \\
Other* & 11 & 6 & 5 \\
Total & 185 & 151 & 34 \\
\hline
\end{tabular}

* Other includes: reproductive system (3), musculoskeletal (3), hepatobiliary (2), cardiac or circulatory (2), neutropenic, fever

in the cumulative incidence of infections between telaprevir and boceprevir $(\mathrm{p}=0.712)$.

\section{Neutrophil counts and infections}

At baseline, mean ANC was 3454/ $\mu \mathrm{L}$ (SD 1532) and 21 (of 284 available measurements) patients had severe neutropenia. Only $5(24 \%)$ of these patients developed an infection (1 severe). Neutrophil count dropped by an average of 2201/ $\mu \mathrm{L}$ (SD 1339) during treatment. A total of 310 (74\%) of 419 patients with available ANC measurements (48 patients had 

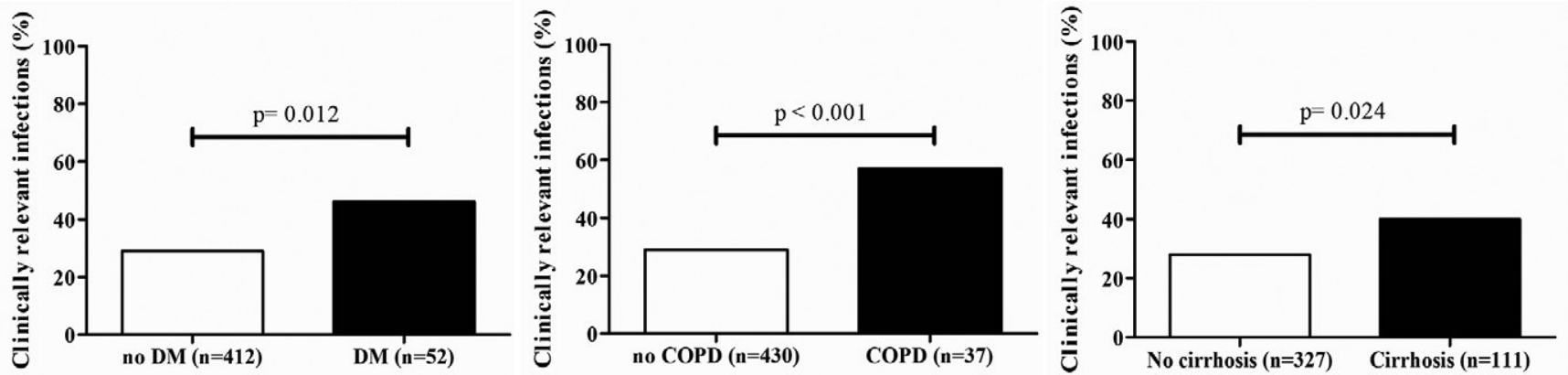

Fig. 2. Clinically relevant infections among patients with known risk factors. The bars represent the percentage of patients who experienced a clinically relevant infection: $2 \mathrm{a}$ ) patients with and without diabetes mellitus (DM); 2 b) patients with and without chronic obstructive pulmonary disease (COPD); 2c) patients with and without cirrhosis.

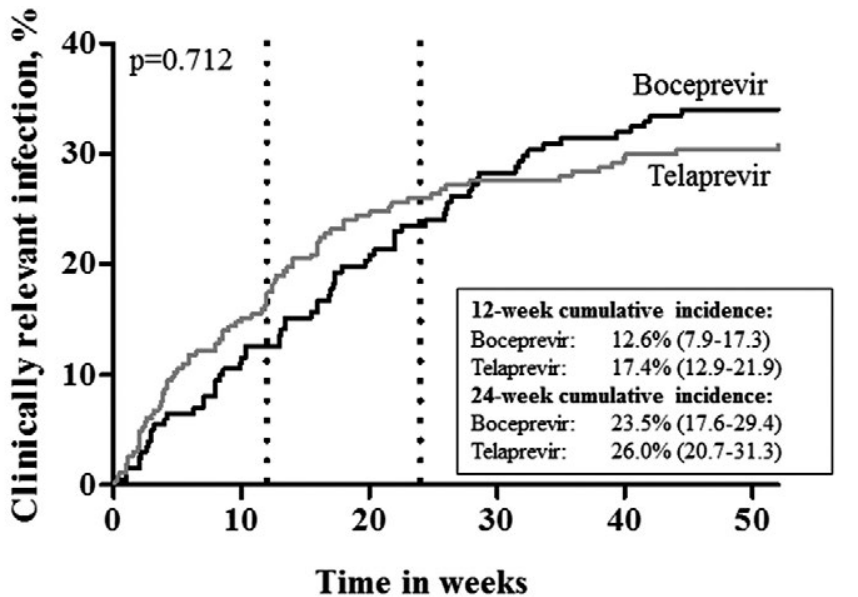

Fig. 3. Kaplan-Meier curves showing the occurrence of the first clinically relevant infection during treatment in patients treated with either telaprevir or boceprevir (12-weeks and 24-weeks cumulative incidence rates)

no ANC tests available) experienced neutropenia during treatment. There were more neutropenia episodes in patients treated with boceprevir than with telaprevir (83\% vs. $67 \%$, $\mathrm{p}<0.001$ ), and we detected a trend towards a higher cumulative incidence of severe neutropenia among patients treated with boceprevir ( $p=0.052$, Fig. 4 ). The median time to nadir neutrophil count per patient was 16 weeks (IQR 8-24 weeks), this was similar for both DAAs.

In 127 of 185 (69\%) clinically relevant infections, neutrophil count from the previous visit had been recorded and median neutrophil count prior to infection was $1600 / \mu \mathrm{L}$ (IQR 1.1-2.3).

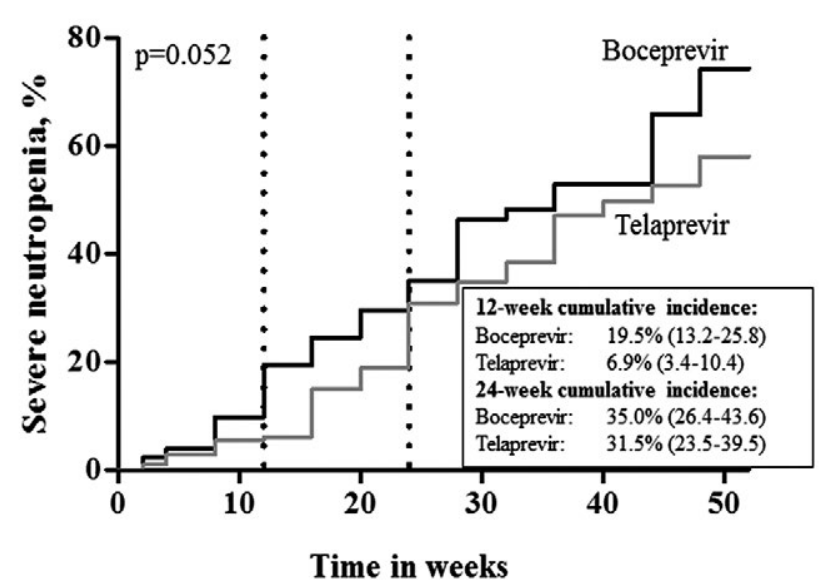

Fig. 4. Kaplan-Meier curves showing the development of severe neutropenia during treatment in patients treated with either telaprevir or boceprevir (12-weeks and 24-weeks cumulative incidence rates).

Overall, 57 times a clinically relevant infection was diagnosed (moderate $n=50$; severe $n=7$ ) in patients who had neutropenia at the preceding visit (89\% mild). By contrast, 1456 visits with neutropenia (96\%) were not followed by an infection.

\section{Risk factors for infection}

Results of univariable and multivariable logistic regression analysis are shown in Table IV. Neutropenia at the previous visit was not associated with occurrence of infections (univariable OR 0.85, 95\%CI 0.57-1.27). Furthermore moderate or severe neutropenia ( $\mathrm{ANC}<750 / \mu \mathrm{L}$ ) seemed to be predictive for

Table III. Sites and diagnoses of severe infections

\begin{tabular}{|c|c|c|}
\hline Site of infection & No of infections & Diagnoses \\
\hline Respiratory & 14 & $\begin{array}{l}\text { Pneumonia (6), pneumonia and exacerbation of chronic obstructive pulmonary disease (4), } \\
\text { respiratory tract infection (3), viral pleuritis }\end{array}$ \\
\hline General & 5 & Sepsis, febris e causa ignota (3), fever after transfusion of packed cells \\
\hline Dermatological & 5 & Abcess, cellulitis, erysipelas, impetigo bacteremia, wound infection after sigmoid resection \\
\hline Renal - urinary tract & 2 & Complicated urinary tract infection, urosepsis \\
\hline $\begin{array}{l}\text { Gastro-intestinal } \\
\text { (incl. oral infections) }\end{array}$ & 2 & Tooth abscess, gastro-enteritis \\
\hline Ophtalmology & 1 & Bacterial eye infection \\
\hline Other & 5 & $\begin{array}{l}\text { Spontaneous bacterial peritonitis (SBP), neutropenic fever, endocarditis, staphylococcal } \\
\text { sepsis after phlebitis, osteomyelitis }\end{array}$ \\
\hline
\end{tabular}


Table IV. Logistic regression analysis with correction for multiple measurements within a patient.

\begin{tabular}{|c|c|c|c|c|}
\hline Variable & Univariable OR (95\% CI) & p-value & Multivariable OR (95\% CI) & p-value \\
\hline Age & $1.019(0.997-1.042)$ & 0.091 & & \\
\hline Female sex & $1.728(1.243-2.401)$ & 0.001 & $1.722(1.169-2.534)$ & 0.006 \\
\hline Body mass index & $0.997(0.933-1.064)$ & 0.917 & & \\
\hline Cirrhosis & $1.767(1.135-2.751)$ & 0.012 & $1.398(0.921-2.122)$ & 0.116 \\
\hline Treatment experienced & $1.136(0.758-1.702)$ & 0.537 & & \\
\hline Telaprevir vs. boceprevir & $1.144(0.766-1.708)$ & 0.510 & & \\
\hline History of decompensated liver disease & $1.850(0.838-4.082)$ & 0.128 & & \\
\hline Diabetes mellitus & $1.737(0.959-3.146)$ & 0.069 & $1.734(1.008-2.983)$ & 0.047 \\
\hline Chronic obstructive pulmonary disease & $3.117(1.811-5.366)$ & $<0.001$ & $2.701(1.635-4.463)$ & $<0.001$ \\
\hline Use of corticosteroids at baseline & $2.312(1.081-4.946)$ & 0.031 & & \\
\hline Leucocyte count per $\mu \mathrm{L}$ & $0.995(0.903-1.096)$ & 0.917 & & \\
\hline Neutrophil count per $\mu \mathrm{L}$ & $1.066(0.938-1.211)$ & 0.329 & & \\
\hline Absolute neutrophil count $<1500$ per $\mu \mathrm{L}$ & $0.850(0.570-1.266)$ & 0.423 & & \\
\hline Absolute neutrophil count $<750$ per $\mu \mathrm{L}$ & $0.448(0.203-0.989)$ & 0.047 & & \\
\hline Baseline albumin, g/L & $0.973(0.925-1.024)$ & 0.293 & & \\
\hline Albumin < $35 \mathrm{~g} / \mathrm{L}$ & $1.608(0.820-3.151)$ & 0.167 & & \\
\hline Platelet count, $\mathrm{x} 10^{9} / \mathrm{L}$ & $0.996(0.993-0.999)$ & 0.007 & & \\
\hline Platelet count $<100 \times 10^{9} / \mathrm{L}$ & $1.619(0.837-3.131)$ & 0.152 & & \\
\hline Albumin $<35 \mathrm{~g} / \mathrm{L}$ and platelet count $\left.<100 \times 10^{9} / \mathrm{L}\right)$ & $3.091(0.974-9.813)$ & 0.056 & & \\
\hline Bilirubin, g/dL & $1.001(0.999-1.002)$ & 0.388 & & \\
\hline
\end{tabular}

OR=Odds Ratio; 95\% CI= 95\% Confidence Interval

infections (OR 0.45, 95\%CI 0.20-0.99), however this was not significant in the multivariable model. The final multivariable analysis identified female gender (OR 1.7, 95\%CI 1.2-2.5), COPD (OR 2.7, 95\%CI 1.6-4.5) and presence of DM (OR1.7, $95 \%$ CI 1.0-3.0) as risk factors for infections. The presence of cirrhosis did not reach significance (OR 1.4, 95\%CI 0.92.1). When adding mild infections to the regression analysis, COPD and female gender remained risk factors, while DM lost significance $(\mathrm{p}=0.11)$.

\section{DISCUSSION}

Our study demonstrates that a 24-48-week course with boceprevir or telaprevir, PegIFN and RBV for $\mathrm{CHC}$ is associated with a high incidence $(31 \%)$ of clinically relevant infections. Within the first 12 weeks, the cumulative incidence of infections was $13-17 \%$ depending on the type of PI. Skin and respiratory infections were the most commonly seen. The infection incidence rates resemble the rates of $12-26 \%$ which are reported in the literature for PegIFN based therapy with and without a PI, indicating the magnitude of this problem [12-14, 22-24, 27-29]. The CUPIC cohort was the first cohort that signaled the high risk for severe infection with first-generation PIs in cirrhotic patients, and identified two important risk factors: baseline albumin below $35 \mathrm{~g} / \mathrm{L}$ and baseline platelet count $\leq 100 \mathrm{x} 10^{\%} / \mathrm{L}$ [23]. Out of the cirrhotic patients in our cohort $(n=111), 12$ patients had both risk factors, and 5 (42\%) developed a severe infection, comparable to the CUPIC cohort (51.4\%). Presence of only one risk factor led to a severe infection in $22 \%$ (albumin < $35 \mathrm{~g} / \mathrm{L}$ ) and $8 \%$ (platelets $\leq 100 \times 10^{9} / \mathrm{L}$ ) of patients with cirrhosis, again resembling CUPIC data [23]. Still, the combined risk factors were not identified as predictor for clinically relevant infections here. The independent factors that drove the risk for infection in our study were female sex, DM and COPD, but not neutropenia. The association of female sex with infections during CHC therapy has been reported previously and was explained by a higher incidence of urinary tract infections (UTI) or vaginal infections $[13,27]$. Our findings are in agreement with these studies as $14 \%$ of clinically relevant infections were UTIs or vaginal infections $(n=26)$ and $92 \%$ of these were observed in females. Another explanation might be the higher incidence of cirrhosis in females compared to males in our cohort $(54 \%$ vs. $22 \%)$. Cirrhosis is established as a risk factor for infection in the literature, whilst our cohort only showed a trend for significance in the multivariable analysis [30-32]. The higher proportion of females with cirrhosis in our cohort might have influenced the regression analysis. Diabetes mellitus is a known risk factor for infection, but it is also associated with $\mathrm{CHC}$ [33]. A higher infection rate in diabetic $\mathrm{CHC}$ patients was therefore hypothesized and could be explained by various factors, such as vascular insufficiency and impaired leucocyte function in these patients $[12,13,34,35]$. Our study implies that diabetic patients should be monitored for infection during $\mathrm{CHC}$ therapy. The only other triple therapy cohort study that assessed risk of infection was restricted to cirrhotics and found that respiratory infections were overrepresented in those on PI therapy [22]. Our cohort supports this finding, as respiratory infections accounted for $41 \%$ of severe infections and $19 \%$ of moderate infections. The identified risk factor COPD might relate to this, as COPD is a known risk factor for respiratory infections [36].

The risk factors in our study (female sex, DM and COPD) are factors that cannot be influenced and are not related to 
the type of $\mathrm{CHC}$ therapy. They are furthermore identified by previous $\mathrm{CHC}$ cohorts with (Peg)IFN and RBV regimes [12, $13,36,37]$. It is therefore likely that they remain risk factors for infection in future IFN-containing $\mathrm{CHC}$ regimes, thus these patients should be monitored carefully for infection during any PegIFN based regime.

Drug induced neutropenia is thought to be an important risk factor for infection. This stems from oncologic research as development of neutropenia following chemotherapy usually heralds a severe clinical situation necessitating admission and prompt administration of antibiotics [38]. There is a wealth of literature that establishes that PegIFN induced neutropenia does not pose an increased risk for infections in CHC patients $[12,22,39]$. Indeed, in our cohort neutropenia did not increase the risk of infection; it even seemed to be associated with a lower risk for infections. Altogether this suggests that neutropenia due to chemotherapy is different from that due to PegIFN. Oncology patients differ in factors which affect susceptibility for infection such as alteration of organ function caused by their underlying disease and presence of mucosal damage [40, 41]. Because these findings are absent in stable $\mathrm{CHC}$ patients, it is reasonable to believe that $\mathrm{CHC}$ patients receiving triple therapy are less immune-compromised than oncology patients and that thresholds for PegIFN dose reductions, based on the presence of neutropenia, may be too strict.

The advent of new generation DAAs allows to pinpoint the culprit for neutropenia in CHC. Neutropenia still occurs with any PegIFN containing regimen regardless of the DAA included [42-45]. IFN-free regimens do not cause neutropenia suggesting that PegIFN is the cause rather than CHC, DAA or RBV [43]. Here, boceprevir was associated with higher neutropenia rates than telaprevir. Whether this PI interacts with PegIFN for inducing neutropenia or whether it is a class effect of the PIs, cannot be assessed in this study. This finding should be interpreted with caution. Despite the higher incidence of neutropenia, infection rate was comparable between both drugs, confirming the lack of association between neutropenia and infections in $\mathrm{CHC}$ therapy.

The strengths of this study are both the size of our real world cohort and its nationwide character. Unique to our cohort is that it includes $\mathrm{CHC}$ patients across all fibrosis stages in the Netherlands and is not limited to cirrhotic patients. Patients visited the clinic frequently resulting in detailed records. However, the retrospective design enhances the risk of reporting bias. We made an effort to minimize this risk by adhering to a strict definition of severity of infections and restricting our analysis to infections necessitating antiinfective therapy. Furthermore, telaprevir and boceprevir are first generation DAAs that have lost market share in view of the advent of more effective and better tolerable new generation DAAs. However, these drugs continue to be used in economically deprived countries that use PegIFN as a backbone for CHC therapy $[46,47]$.

\section{CONCLUSION}

Our real world nationwide cohort study showed that the incidence of infections during PegIFN-based triple therapy is high, even among patients without cirrhosis. Neutropenia occurs frequently, but does not increase the risk for infection. Female gender, DM and COPD, however, are risk factors for infection and are independent of type of CHC therapy, suggesting that these patients should be carefully monitored for infections once a PegIFN-based regimen is initiated.

Conflicts of interest: F. Berden and I. van Zwietering have nothing to disclose; R. Maan received financial compensation for consultancy activities from AbbVie; R. de Knegt reports other from Gilead, grants and other from Janssen, BMS, AbbVie, Roche, other from Norgine, outside the submitted work; W. Kievit has nothing to disclose; J. Drenth reports other from Gilead, grants and other from Janssen, AbbVie, other from BMS, grants from dr. Falk, Ipsen, Novartis, Zambon, Merck, outside the submitted work.

Acknowledgements. The authors would like to thank the physicians and nurses of all cooperating Dutch hepatitis treatment centers for their contribution to this study.

Financial disclosure. No funding was obtained.

Authors' contribution: F.B.: study concept and design; acquisition of data; statistical analysis and interpretation of data; drafting of the manuscript; I.v.Z.: acquisition of data; statistical analysis and interpretation of data; drafting of the manuscript; R.M.: statistical analysis and interpretation of data; drafting of the manuscript; R.J.dK.: interpretation of data, critical revision of the manuscript for important intellectual content; W.K.: study concept and design; critical revision of the manuscript for important intellectual content, study supervision; J.D.: study concept and design; critical revision of the manuscript for important intellectual content; study supervision.

Supplementary material: To access the supplementary material visit the online version of the J Gastrointestin Liver Dis at http://www.jgld. ro/wp/archive/

\section{REFERENCES}

1. Chou R, Hartung D, Rahman B, Wasson N, Cottrell EB, Fu R. Comparative effectiveness of antiviral treatment for hepatitis $\mathrm{C}$ virus infection in adults: a systematic review. Ann Intern Med 2013; 158: 114-123. doi: 10.7326/0003-4819-158-2-201301150-00576

2. Kohli A, Shaffer A, Sherman A, Kottilil S. Treatment of hepatitis C: a systematic review. JAMA 2014; 312: 631-640. doi: 10.1001/ jama.2014.7085

3. Mohd Hanafiah K, Groeger J, Flaxman AD, Wiersma ST. Global epidemiology of hepatitis $C$ virus infection: new estimates of age-specific antibody to HCV seroprevalence. Hepatology 2013; 57: 1333-1342. doi: 10.1002/hep.26141

4. Stanciu C, Trifan A. Hepatitis C Virus Treatment Revolution: Eastern European Story. Hepat Mon 2015; 15: e28969. doi: 10.5812/ hepatmon.28969v2

5. Sporea I, Curescu M, Sirli R."Standard of care" treatment for chronic viral C hepatitis in 2013 in Romania. J Gastrointestin Liver Dis 2013; 22: 360-361.

6. Omata M, Kanda T, Yokosuka O, et al. Features of hepatitis $\mathrm{C}$ virus infection, current therapies and ongoing clinical trials in ten Asian 
Pacific countries. Hepatol Int 2015; 9: 486-507. doi: 10.1007/s12072015-9630-4

7. European Association for Study of Liver. EASL Recommendations on Treatment of Hepatitis C 2015. J Hepatol 2015; 63: 199-236. doi: 10.1016/j.jhep.2015.03.025

8. Worid Health Organization. Guidelines for the screening, care and treatment of persons with hepatitis C infection. 2014. Available at: http://www.who.int/hiv/pub/hepatitis/hepatitis-c-guidelines/en/

9. Peck-Radosavljevic M, Wichlas M, Homoncik-Kraml M, et al. Rapid suppression of hematopoiesis by standard or pegylated interferon-alpha Gastroenterology 2002; 123: 141-151. doi: 10.1053/gast.2002.34175

10. Gheorghe L, Iacob S, Simionov I, et al. A real life boceprevir use in treatment-experienced HCV genotype 1 patients with advanced fibrosis. J Gastrointestin Liver Dis 2014; 23: 45-50.

11. World Health Organization. Guidelines for the screening, care and treatment of persons with hepatitis C infection. Geneva 2014.

12. Roomer R, Hansen BE, Janssen HL, de Knegt RJ. Risk factors for infection during treatment with peginterferon alfa and ribavirin for chronic hepatitis C. Hepatology 2010; 52: 1225-1231. doi: 10.1002/ hep. 23842

13. Maan R, van der Meer AJ, Hansen BE, et al. Risk of infections during interferon-based treatment in patients with chronic hepatitis $\mathrm{C}$ virus infection and advanced hepatic fibrosis. J Gastroenterol Hepatol 2015; 30: 1057-1064. doi: 10.1111/jgh.12929

14. Antonini MG, Babudieri S, Maida I, et al. Incidence of neutropenia and infections during combination treatment of chronic hepatitis $\mathrm{C}$ with pegylated interferon alfa-2a or alfa-2b plus ribavirin. Infection 2008; 36: 250-255. doi: 10.1007/s15010-007-7132-6

15. Striki A, Manolakopoulos S, Deutsch M, et al. Cirrhosis but not neutropenia is associated with the development of infection in patients with chronic hepatitis $\mathrm{C}$ undergoing treatment with pegylated interferon-alpha and ribavirin. J Viral Hepat 2014; 21: 624-632. doi: 10.1111/jvh. 12197

16. Yang JF, Hsieh MY, Hou NJ, et al. Bacterial infection and neutropenia during peginterferon plus ribavirin combination therapy in patients with chronic hepatitis $\mathrm{C}$ with and without baseline neutropenia in clinical practice. Aliment Pharmacol Ther 2009; 29: 1000-1010. doi: 10.1111/j.1365-2036.2009.03957.x

17. Janczewska E, Flisiak R, Zarebska-Michaluk D, et al. Effect of Peginterferon or Ribavirin Dosing on Efficacy of Therapy With Telaprevir in Treatment-Experienced Patients With Chronic Hepatitis C and Advanced Liver Fibrosis: A Multicenter Cohort Study. Medicine (Baltimore) 2015; 94: e1411. doi: 10.1097/MD.0000000000001411

18. Poordad F, McCone J Jr, Bacon BR, et al. Boceprevir for untreated chronic HCV genotype 1 infection. N Engl J Med 2011; 364: 1195-1206. doi: 10.1056/NEJMoa1010494

19. Bacon BR, Gordon SC, Lawitz E, et al; HCV RESPOND-2 Investigators Boceprevir for previously treated chronic HCV genotype 1 infection. N Engl J Med 2011; 364: 1207-1217. doi: 10.1056/NEJMoa1009482

20. Backus LI, Belperio PS, Shahoumian TA, Cheung R, Mole LA. Comparative effectiveness of the hepatitis $\mathrm{C}$ virus protease inhibitors boceprevir and telaprevir in a large U.S. cohort. Aliment Pharmacol Ther 2014; 39: 93-103. doi: 10.1111/apt.12546

21. Salmeron J, Vinaixa C, Berenguer R, et al; Alhambra Spanish Study Group. Effectiveness and safety of first-generation protease inhibitors in clinical practice: Hepatitis $\mathrm{C}$ virus patients with advanced fibrosis. World J Gastroenterol 2015; 21: 9163-9174. doi: 10.3748/wjg.v21. i30.9163
22. Londono MC, Perelló C, Cabezas J, et al. The addition of a protease inhibitor increases the risk of infections in patients with hepatitis C-related cirrhosis. J Hepatol 2015; 62: 311-316. doi: 10.1016/j. jhep.2014.09.025

23. Hezode C, Fontaine H, Dorival C, et al. Effectiveness of telaprevir or boceprevir in treatment-experienced patients with HCV genotype 1 infection and cirrhosis. Gastroenterology 2014; 147: 132-142 e4. doi: 10.1053/j.gastro.2014.03.051

24. Hezode C, Fontaine H, Dorival C, et al. Triple therapy in treatmentexperienced patients with HCV-cirrhosis in a multicentre cohort of the French Early Access Programme (ANRS CO20-CUPIC) - NCT01514890. J Hepatol 2013; 59: 434-441. doi: 10.1016/j. jhep.2013.04.035

25. Lamers MH, Broekman MM, Boucher CA, et al. Treatment of hepatitis C monoinfection in adults--Dutch national guidelines. Neth J Med 2013; 71: 377-385.

26. Sterling RK, Lissen E, Clumeck N, et al; APRICOT Clinical Investigators. Development of a simple noninvasive index to predict significant fibrosis in patients with HIV/HCV coinfection. Hepatology 2006; 43: 1317-1325. doi: 10.1002/hep.21178

27. Melia MT, Bräu N, Poordad F, et al. Infections during peginterferon/ ribavirin therapy are associated with the magnitude of decline in absolute lymphocyte count: results of the IDEAL study. Clin Infect Dis 2014; 58: 960-969. doi: 10.1093/cid/ciu009

28. Colombo M, Strasser S, Moreno C, et al. Sustained virological response with telaprevir in 1,078 patients with advanced hepatitis C: the international telaprevir access program. J Hepatol 2014; 61: 976-983. doi: 10.1016/j.jhep.2014.06.005

29. Gordon SC, Muir AJ, Lim JK, et al; HCV-TARGET study group. Safety profile of boceprevir and telaprevir in chronic hepatitis C: real world experience from HCV-TARGET. J Hepatol 2015; 62: 286-293. doi: 10.1016/j.jhep.2014.08.052

30. Jalan R, Fernandez J, Wiest R, et al. Bacterial infections in cirrhosis: a position statement based on the EASL Special Conference 2013. J Hepatol 2014; 60: 1310-1324. doi: 10.1016/j.jhep.2014.01.024

31. Fernandez J, Gustot T. Management of bacterial infections in cirrhosis. J Hepatol 2012; 56 Suppl 1: S1-S12. doi: 10.1016/S0168-8278(12)60002-6

32. Foreman MG, Mannino DM, Moss M. Cirrhosis as a risk factor for sepsis and death: analysis of the National Hospital Discharge Survey. Chest 2003; 124: 1016-1020. doi: 10.1378/chest.124.3.1016

33. White DL, Ratziu V, El-Serag HB. Hepatitis C infection and risk of diabetes: a systematic review and meta-analysis. J Hepatol 2008; 49: 831-844. doi: 10.1016/j.jhep.2008.08.006

34. Delamaire M, Maugendre D, Moreno M, Le Goff MC, Allannic H, Genetet B. Impaired leucocyte functions in diabetic patients. Diabet Med 1997; 14: 29-34. doi: 10.1002/(SICI)1096-9136(199701)14:1<29::AIDDIA300 $>3.0 . C O ; 2-\mathrm{V}$

35. Llorente L, De La Fuente H, Richaud-Patin Y, et al. Innate immune response mechanisms in non-insulin dependent diabetes mellitus patients assessed by flow cytoenzymology. Immunol Lett 2000; 74: 239-244. doi: 10.1016/S0165-2478(00)00255-8

36. Torres A, Blasi F, Dartois N, Akova M. Which individuals are at increased risk of pneumococcal disease and why? Impact of COPD, asthma, smoking, diabetes, and/or chronic heart disease on communityacquired pneumonia and invasive pneumococcal disease. Thorax 2015; 70: 984-989. doi: 10.1136/thoraxjnl-2015-206780

37. Zhang Y, Zheng QJ, Wang S, et al. Diabetes mellitus is associated with increased risk of surgical site infections: A meta-analysis of prospective 
cohort studies. Am J Infect Control 2015; 43: 810-815. doi: 10.1016/j. ajic.2015.04.003

38. Lyman GH, Michels SL, Reynolds MW, Barron R, Tomic KS, Yu J. Risk of mortality in patients with cancer who experience febrile neutropenia. Cancer 2010; 116: 5555-5563. doi: 10.1002/cncr.25332

39. Serrano-Villar S, Quereda C, Moreno A, et al. Neutropenia during therapy with peginterferon and ribavirin in HIV-infected subjects with chronic hepatitis C and the risk of infections. Clin Infect Dis 2013; 57: 458-464. doi: $10.1093 / \mathrm{cid} / \mathrm{cit} 221$

40. Viscoli C. The evolution of the empirical management of fever and neutropenia in cancer patients. J Antimicrob Chemother 1998; 41 Suppl D: 65-80. doi: 10.1093/jac/41.suppl_4.65

41. Bodey GP, Buckley M, Sathe YS, Freireich EJ. Quantitative relationships between circulating leukocytes and infection in patients with acute leukemia. Ann Intern Med 1966; 64: 328-340. doi: 10.7326/0003-481964-2-328

42. Manns MP, Fried MW, Zeuzem S, et al. Simeprevir with peginterferon/ ribavirin for treatment of chronic hepatitis $\mathrm{C}$ virus genotype 1 infection pooled safety analysis from Phase IIb and III studies. J Viral Hepat 2015; 22: 366-375. doi: 10.1111/jvh.12346

43. Banerjee D, Reddy KR. Review article: safety and tolerability of directacting anti-viral agents in the new era of hepatitis $\mathrm{C}$ therapy. Aliment Pharmacol Ther 2016; 43: 674-696. doi: 10.1111/apt.13514

44. Mangia A, Piazzolla V. Overall efficacy and safety results of sofosbuvirbased therapies in phase II and III studies. Dig Liver Dis 2014; 46 Suppl 5: S179-S185. doi: 10.1016/j.dld.2014.09.026

45. Narayanan S, Townsend K, Macharia T, et al. Favorable adverse event profile of sofosbuvir/ribavirin compared to boceprevir/interferon/ ribavirin for treatment of hepatitis C. Hepatol Int 2014; 8: 560-566. doi: 10.1007/s12072-014-9574-0

46. Lim SG, Dan YY. A 2015 roadmap for the management of hepatitis C virus infections in Asia. Korean J Intern Med 2015; 30: 423-433. doi: 10.3904/kjim.2015.30.4.423

47. Edwards DJ, Coppens DG, Prasad TL, Rook LA, Iyer JK. Access to hepatitis C medicines. Bull World Health Organ 2015; 93: 799-805. doi: 10.2471/BLT.15.157784 


\section{Supplementary Fig. 1. Study flowchart}

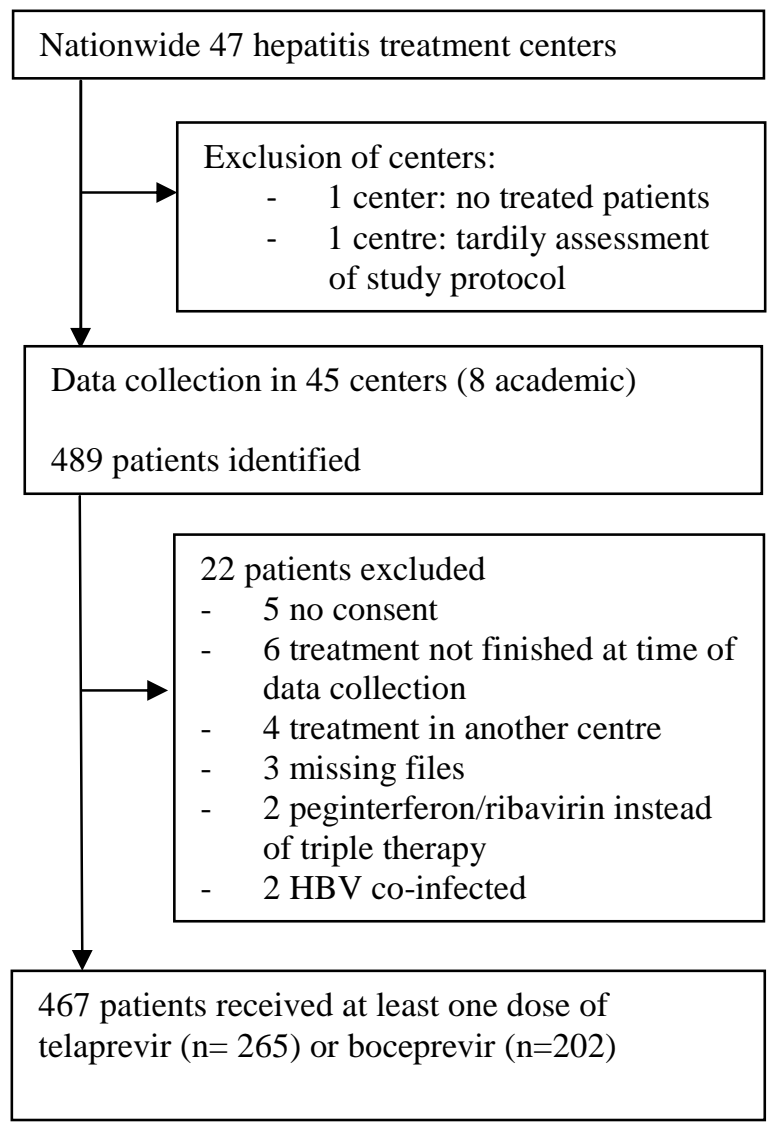

